\section{climital electure}

ON

\section{PARALYSIS OF THE MUSCLES OF THE EYE.}

DELIVERED AT THE LONDON HOSPITAL. BY

JONATHAN HUTCHINSON, Esq., Assistant. Surgeon, and Lecturer on Surgery.

Gextuemen,-In the man before us, the upper lid of the left eye droops so much that it meets the lower one, and that the front of the globe is wholly concealed. He has not the slightest power of raising the lid. It is very rare that ptosis (such is the learned name for this symptom) is so complete as we here see it. Much more generally it comes before us as a mere dropping of the lid, with imperfect power of raising it ; very seldom indeed do we see it in so extreme a state. If we raise the dropped lid, other very interesting conditions present themselves. Instead of looking forwards, the man's eye is directed out, and looks right away over its possessor's shoulder. If we look nearer, we shall notice that the pupil is much dilated, it being at least four times the size of the other. If we ask the man to look to the right, we observe his right eye pass easily outwards; the left, on the other hand, is merely liberated, so to speak, until it looks nearly straight forwards; but further than that he cannot draw it. If he tries to look upwards or downwards, the right globe obeys his volition, but the left remains quite fixed. Thus, then, we have proof that the inner rectus of the left eye, the superior and inferior recti, the levator of the upper lid, and the constrictor of the pupil, are all of them paralysed. All these muscles are supplied by one and the same nerve; and the case is, therefore, clearly one of complete paralysis of the third nerve or motor oculi. There is, as you are well aware, one other little muscle in the orbit which is supplied by the same nerve; namely, the inferior oblique. No doubt this muscle is also paralysed; but the fact that it is so is not easily demonstrable, since its action upon the eyeball is not so definite and conspicuous as are those of the other muscles. In addition to the muscles we have mentioned, there are two others in the orbit which move the eye-the external rectus and the inferior oblique. Neither of these is supplied by the third nerve, and neither of these is in this case affected. As you see, the external rectus is in full action; the man squints terribly ; and, to prove that the superior oblique retains its activity, you have but to tell him to look downwards, when you will notice the globe to rotate slightly but decidedly on its axis, in a direction downwards and outwards. This rotation is the effect of the superior oblique.

Let us now see if the man's sight is impaired-if there is anything amiss with his optic nerve or retina. To gain this knowledge, we must not only cover his other eye, but we must supply him with a diaphragm, in order to get rid of the inconvenience of a widely dilated pupil; and it will be needful also to hold the object carefully in the right axis of vision, since the man has no power of adjusting the position of his globe. As Mahomet cannot go to the mountain, the mountain must be brought to Mahomet. It would take up time unnecessarily to go through this now; and so I may be content to state that, on trying him carefully yesterday, I ascertained that he could read ordinary type with tolerable ease. The retina is therefore, no doubt, in a perfectly normal state; and we have before us an example of complete paralysis of the third nerve pure and uncomplicated. It is, indeed, one of the instances in which morbid processes present us with a most interesting physiological experiment. If we had cut down upon the third nerve just before its entry into the orbit, and divided it with scissors, without any disturbance or irritation of the adjacent parts (an experiment, of course, quite impossible), we should then expect exactly the condition of things which we have here ready prepared to our hand. We will therefore not neglect our present opportunity. I shall ask you to look in some detail into the nature and real meaning of the various symptoms presented to us. The case, although, as I stated, in itself a rare one, will yet throw light on a large group of others, examples of which very frequently come under our notice. If we master the explanation of the symptoms in this man, our minds will in future be well prepared to investigate some of the very important diagnostic and prognostic symptoms presented by the eye in cases of injury to the head, in cases of apoplectic and other seizures, as well as in those affections in which ptosis or dilatation of one pupil indicate, it may be, either a slight rheumatic neurosis, or the supervention of important cerebral mischief. Several of those present will remember well the case of a man who was admitted a few weeks ago in profound coma, after a fall on his head. He. had sustained a compound fracture, with slight depression of the right parietal bone. His left pupil was dilated, and his left eye divergent-symptoms which led us, first, to the knowledge that his left third nerve was paralysed; and secondly, in the absence of general hemiplegia, to the important inference that he had sustained a fracture of the base of his skull. This opinion I expressed at the time ; and although, in the existence of a fracture superficially, I deemed it right to employ the trephine, it was with but little hope of benefit. The autopsy showed that the inference had been quite correct. But let us revert to our patient.

History of the Case. Alfred B., the man before us, is, as you see, a pale yellow complexioned man, of spare habit. His age is 29 , his occupation that of a butcher ; and, when at home, he lives at the healthy town of Dorking. He states that he has drunk rather freely, but avers that he has never had syphilis. He had gonorrhœa five or six years ago ; but no bubo, rash, or sore-throat, followed it. He has never been liable to rheumatism, nor has he suffered from headaches. Two months ago, he had a bad cold in the head, attended with hoarseness and some cough. This lasted about a week, and pulled him down a good deal. He had, however, been well of it for a fortnight before he noticed his left eyelid to begin to droop. He considered himself in usual health when this came on, and he had with it neither pain nor ache in any part. His appetite, sleep, etc., remained just as they had been; and he had no cerebral symptoms whatever, excepting those of the third nerve, to which we have adverted. He describes the drooping of the lid as having come on gradually, and 
several days were occupied before it was complete. At this time-i.e., before the pupil had been covered by the lid-he saw objects double.

He first came under my care on November 18th, three weeks from the commencement of his symptoms. His state then was exactly what we now see it. We have used blisters to the temple and neck, and prescribed the iodide of potassium internally; but hitherto with but little benefit. He cannot yet raise his lid at all; but he decidedly possesses a slight power over the inner rectus, which was not present at first, and which is a hopeful symptom as regards the ultimate result. I may state that, during the fortnight he has been under my notice, his tongue has been clean. We have examined his urine, and find it rather pale, of low specific gravity, and free from albumen. There is, therefore, apart from his general cachexia of appearance, not a single constitutional symptom for us to take hold of. On what are we to suppose that the paralysis depends? We are obliged to consider the cause as in all probability mechanical-that is, pressure on the nerve-trunk; for the suspension of function is too complete for us to refer it to mere functional interruption of endowment. In all probability, the nerve is so pressed upon in some part of its course that it is as much interrupted in its continuity as if it were cut across. The trunk of the third nerve is not a long one; it emerges from the brain on the inner aspect of the crus cerebri, being a firm white cord, about the thickness of three pins. It passes forwards between the superior cerebellar and posterior cerebral arteries, and, after a course of about an inch, enters the outer wall of the cavernous sinus, which it finally leaves to gain the orbit through the sphenoidal fissure. Before entering the orbit, it has already divided into two branches. It is clear that the disease in this instance is not in the orbit; since, if it were, it would probably implicate only one of the two divisions of the trunk, whereas all the muscles are equally paralysed. Any tumour, such as aneurism, existing in the cavernous sinus might press upon the trunk of the third nerve, and arrest its function; but it is improbable that, in doing so to the effect of complete arrest, it would fail also to press somewhat on the fourth, and on the ophthalmic division of the fifth, both of which lie close to the third. If it were an aneurism of the carotid artery, the sixth nerve would be the one most likely to be pressed upon. Such has, indeed, been the clinical fact in several of the cases of this lesion which are on record. Now, in our case, the third alone is affected. It is probable, therefore, that the point at which the nerve is compressed is not in the cavernous sinus. We have then left the tract intervening between the sinus and the erus cerebri; and lastly, the crus itself, and the tract of brain-substance through which the nerve-fibres pass to their deep origin. It is improbable that there is any disease in the substance of the crus, such as softening blood-clot or tumour; because, if there were, there ought certainly to be symptoms of cerebral disease more complex than the single one of paralysis of the third nerve. We come, then, by the process of exclusion, to the opinion that the tract of nerve between the crus cerebri and the cavernous sinus is the one in which, in all probability, the lesion exists. In this part, the nerve is isolated, and as it were free in the cranial cavity, invested only by its own sheath of arachnoid. It is possible that blood may have been effused within this sheath, thus compressing the nerve-tubules; or the effusion may not have been blood, but some inflammatory material. The latter hypothesis I take to be the more probable, because the symptom supervened slowly, not all at once, as it might have been expected to do if extravasation had occurred. This of course is, to a large extent, hypothetical reasoning; but it is necessary to go through with it, because, irrespectively of the satisfaction there is in gaining a clear and definite hypothesis, it is needful that we should do something in the way of treatment; and it is better that our remedies should be directed by reasonable hypothesis than by mere haphazard. Amongst the causes which induce effusions of lymph within the sheaths of nerves, the syphilitic diathesis is undoubtedly by far the most common. Local rheumatism, or more properly, what is known as "catching cold", is probably the next in frequency. Now, although the man in the present instance denies having had syphilis, yet it is still quite possible that he may have had it; and the treatment which I have adopted is one which keeps in view this possibility, whilst it is also directed against a rheumatic element, should such exist. There is no remedy, next to mercury, so efficient in procuring the absorption of lymph, syphilitic or otherwise, as iodide of potassium. In the cachectic state in which the man is, we could not think of mercury; and I have, therefore, ordered him five-grain doses of the iodide, in combination with tonics, three times daily.

We will now direct our attention to the phenomena presented by the girl Ann Tylor, who is now before us.

She came to me in April last, with the history that she had never had anything amiss with her eyes until the previous Thursday. On that day, she had accidentally received a blow from a man's elbow on the temporal region, not far from the outer angle of her right eye. It caused her no symptoms at the time, but the next day she found that she saw double.

Her objective symptoms at the time of her admission were almost exactly what you to-day (six months later) see them. She had simply a convergent squint. That this squint was due to paralysis of the right external rectus was evident; because, when directed to look towards her right shoulder, she was obliged to turn her whole head, being unable to direct her right eye outwards. She saw double whenever objects were presented to the right side, not when straight before her or to the left. With a candle in a dark room, however, she saw double, even when looking straight forwards. The two images seen by the respective eyes were seen on the same side; that is, the clear and definite image seen by the left eye was on the left side of the blurred and indistinct image seen by the right eye on the right. This condition of things still exists, and we can easily demonstrate it by the use of a coloured slip of glass. These symptoms are, indeed, the exact reverse of those presented by the man; the squint is inwards instead of outwards, there is no drooping of the lid, and no dilatation of the pupil.

Asking you to keep clearly in mind that the squint which exists in the two patients before us is essentially different from that form for which you so 
frequently see operations performed, that these are cases of paralysis, whereas the others are cases of spasm, I will now make a few remarks on the special symptoms.

You will often hear ptosis spoken of as if it were a special disease in itself. Remember always that it is simply an indication of paralysis of the third nerve; and whenever you observe it inquire about double vision, and notice whether the pupil be dilated and the eye thrown outwards. In the same way, never, when a patient tells you that he sees double, be content with a surmise that he has something amiss with his brain, or that his liver is out of order. See if other symptoms be not present, closely related to it in their cause. Keep the fact before you that double vision is not caused by brain mischief, but by the altered direction of one of the eyeballs. If one of the eyes is straight and the other oblique, it is impossible but that the patient should see double, however sound his brain may be. It is quite true that this altered direction of the globes may itself be, and mostly is, due to cerebral causes ; but still very often it is not so, and the accuracy of your diagnosis will be much aided by your appreciating clearly the several intermediate conditions by which it is produced. The theory of double vision is simply this. Under usual circumstances, an image of every object we look at is formed upon the retina of each eye ; but we do not see two objects, because the images are formed upon corresponding parts of the retinæ in the two eyes, i.e., upon the yellow spot in each. Let one eye, however, be thrown out of its normal axis, that is, let it squint, and at once the images are formed on non-corresponding parts of the retinæ, and the mind perceives them as two. When two are seen, you will always find it the case that one is elearly seen, the other much less so; the reason of which is that the eye which looks straight receives its image upon the sensitive yellow spot, the other upon some outlying part of the retina which is much less sensitive. The less the extent of the squint, the greater the trouble to the patient from double vision, because the image in the squinting eye is formed very near to its yellow spot, and is seen more clearly, and therefore more confusingly, than if it were further off. Then, too, when the squint is slight, the patient sees the objects almost close together, perhaps overlapping each other, and this is much more confusing than if one were seen at a considerable distance from the other. It was in this condition that Burns describes himself to have been, when returning home from the publichouse, and looking at the moon,

" To count her horns wi' a' my power, I set mysel;

But whether she had three or four, I cou'dna tell."

That is, the want of correspondence between his two eyes was very slight, and the two images of the moon were formed on his two retina very near to each other. Had they been further off he would have seen two moons distinctly, and would have had no difficulty in telling the number of the horns of each. And this leads me to advert to the ordinary causes of double vision. The symptom is very common in the early stages of intoxication, and in this instance, as in almost all others, is due to a want of parallelism between the two globes. The first result of alcoholic poisoning is to prevent the normal coordination of the muscular system; a fact which is made patent in the reeling, uncertain gait, the thick voice, and expressionless features. It is not surprising that this want of coordination should extend to the muscles of the eyeball. In the first stage, a vigorous voluntary effort is quite competent to overcome the defect, and the man who is just beginning to notice an appearance of two flames to the candle or the table can, by a little straining, adjust his eyes and dispel the illusion. If he take more of the poison, the result will, however, in all probability be, that double vision, for the time irremediable, will ensue. A more advanced stage still will be the entire suspension of visual power. The two convivial M.P.s who walked into the House after dinner presented illustrations of these two stages-

"I cannot see the Speaker, Hal, can you?

Not see the Speaker! bless you, I see two!"

Double vision may, however, depend upon any cause affecting the nerves of the eyeball ; and it is to the discovery of which nerve is involved that your investigations must be directed. A young lady of delicate aspect was brought to me one morning with the history that, while sitting in chapel, after having been several hours without food, and feeling much fatigued, she had suddenly observed that there appeared to be two preachers. I found that her left upper lid drooped, and that her left pupil was rather larger than the other. There was no perceptible squint. It was clear that in this instance the third nerve was affected. Not unfrequently in these cases the degree of obliquity will be so slight that you can scarcely observe any squint. As I have explained, the slighter the degree of squint, if there only be a squint, the more troublesome will the double vision be. If neither squint nor ptosis be noticeable, you may be puzzled to say which is the affected eye, and whether the external or internal rectus be defective. Take your patient into a dark room, and let him look at a candle. Then hold a slip of coloured glass before the left eye, and ascertain whether he sees the coloured image on the left of the uncoloured one. If he does so, the want of parallelism is inwards, and it is the sixth nerve which is paralysed. If, on the other hand, the images are seen. crossed, the squint is convergent, and it is the third nerve which is diseased. A good rule for you to remember this by is, that it is the reverse of what you would have expected; black is white, and white is black. When a man squints crosswise he sees the two objects parallel, but when he squints outwards he sees them crossed. If you will try presently with the prisms on the table you will soon see that this is so, but we need not stop at present to explain the optical reason.

You will ask why, if the obliquity of one of the globes causes double vision, do not those who squint always see double. The fact that they do not in ordinary cases is undoubted. I reply that it is a mere matter of habit. A patient with an oblique eye leurns to neglect the impression formed upon it, and attends only to that seen by the well-directed organ. Thus, a recently acquired squint always causes double vision, but in a short time it is not noticed. When we operate for squirt, the patients almost always see double for a week or two afterwards; because the eyes,' although nearly restored to parallelism, have not been exactly so, and the patient requires to get used to their new position. You may always assure 
the patient in such a case that his annoyance from this cause will pass off.

A very interesting experiment may be tried in the artificial production of double vision by the prism, which depends upon the fact that you cannot see double with one eye only. Soldiers, wishing to obtain their discharge, sometimes feign blindness of one eye, and it may be very difficult to tell whether their assertion is true or otherwise. If, without appearing to doubt it, you place a prism and a piece of coloured glass before the sound eye, and inquire as to double vision, you will get the information you want. If the amaurosis is real, but one object will be seen, and that coloured; and if the man complain of seeing two, it is quite certain that he has visual power in both eyes. You may, indeed, ascertain whether his sight is good or imperfect in the eye which he feigns to be blind, by getting him to describe the degree of distinctness with which he sees the uncoloured image as compared with the other, the uncoloured one being, of course, the image seen by the eye he professes to be blind of.

As to the dilatation of the pupil in the case of the man, it depends upon suspension of functions of the sphincter muscle of the iris consequent on paralysis of the third nerve. It is a tolerably constant symptom in association with ptosis and eversion of the globe, but is not often seen to such a degree as we have it here presented.

\section{辛 梁ecture}

\section{ON URINARY CALCULI.}

BY

LIONEL BEALE, M.B., F.R.C.P., F.R.S.,

PHYSICLN TO KING'S COLLEGE hOSPITAL; PROFESSOR OF PHYSIOLOGY AND OF GENERAL AND MORBID ANATOMY IN KING'S COLIEGE, LONDON; ETC.

[ Concluded from $p .59$.

On the Importance of the Administration of increased Quantities of Fluids in certain Calculous and other Affections.

I HAVE already adverted to the importance of in. creasing the quantity of fluid taken by persons who suffer from certain varieties of urinary deposits. This principle has been fully recognised by Prout and many practical physicians who have had experience in treating cases of this class; but the remedy, perhaps from its very simplicity, has certainly not received the attention at the hands of many prac. titioners that it deserves. There are conditions of the system which are very much influenced by the dilution of the blood, and many of the chemical decompositions going on are promoted by an increase in the quantity of fluid. Some changes will not take place unless the solutions of the substances be very dilute. Many comparatively insoluble matters are slowly dissolved away by the frequent renewal of the fluid in contact with them. Even silica is capable of being dissolved in water; and it is from a solution containing so slight a trace that the substance can only be detected at all by operating upon very large quantities, that the whole of the silicious matter contributing in so important a degree to give firmness to the stems of grasses is deposited. The amount of water that must pass through the tissues of the plant during its growth, and give up its silicious matter, must be enormous, since the quantity dissolved in each pint of fluid taken up by the roots is so very small. On the same prin. ciple, by causing much liquid to traverse the tissues of a living animal, comparatively insoluble substances may be washed out. It is doubtful if that abundant deposition of urate of soda which is from time to time met with in almost all parts of the body, in certain cases, would have occurred at all, if the fluids had been constantly maintained in a proper state of dilution; and, when these crystals have been deposited, we endeavuar to remove them, or prevent further deposition, by diluting the fluids of the body, and by endearouring to increase the solubility of the urate. We are perhaps too apt, in many chronic cases, to put patients upon a plan of treatment for so short a time as a few days or weeks ; and our patients are often unreasonable enough to expect that remedies will remove in a week matter which has been slowly accumulating perhaps for years. It is chronic cases of this kind which receive such real benefit from the comparatively prolonged course to which they are subjected in a German bath or hydropathic establishment; and it too often happens that, in endeavouring to perform quickly by remedies that which it is only possible to effect by giving large quantities of fluid during a considerable period of time, we disappoint ourselves and our patients; and perhaps in the end they attribute to some quack remedy or system, to which they have subsequently had recourse, a favourable result which is really due to the water they have drank and the hygienic rules to which they have been subjected, instead of to the nostrums they have swallowed.

In certain case of gout, in chronic rheumatism, and in many cases where uric acid and urates are constantly deposited in the urine or in the tissues of the body, the most important of all things is to ensure the thorough washing out of the system. Exercise when it can be taken, hot baths, Turkish baths, etc., by promoting sweating, excite thirst; and thus more fluid is ingested, which is soon got rid of by various emunctories, carrying out with it insoluble substances, the fluid removed being soon replaced by a fresh quantity. In the frequent repetition of these processes from time to time, a vast quantity of fluid is made to pass through the body, with the most beneficial effect.

You would be surprised how very little fluid some persons take, as a rule; and this fluid, small as it is, is often saturated with soluble substances. The fluid thus introduced is, in many persons who live well, barely sufficient to hold the various compounds in solution while undergoing chemical change. Many dislike to drink water, and not a few have a strong prejudice against it; and these are often the very individuals whom we find suffering from gout, rheumatic pains in the muscular and fibrous tissues, and various forms of urinary deposits. They will receive the greatest benefit from moderate sweating and alkalies dissolved in a large quantity of water. You will seldom find difficulty in prevailing on patients to take Seltzer, Vichy, or other alkaline waters daily, although it would be useless to recommend them to take pure water. They can take them with their wire at dinner, the last thing at night, and perhaps the first thing in the morning. People who live well, or rather too well, will soon find out that they must continue this plan, and take now and then small doses of alkalies. It is quite superfluous for me to enter into the minute details applicable in individual cases; but I cannot too strongly recommend you to study very carefully the different symptoms in cases of this class ; for I feel sure that much permanent relief may be afforded such patients by explaining to them the importance of constantly attending to simple rules based on the principles to which I have adverted. Although I may have been somewhat tedious, I feel sure that you will not think that I have dwelt longer on these points than their practical importance demands; and I am convinced that we 